Bull. Mater. Sci., Vol. 6, No. 6, December 1984, pp. 1035-1039. (C) Printed in India.

\title{
Temperature dependence of microhardness in mixed crystals
}

\author{
SANKAR P SANYAL and R K SINGH \\ Department of Physics, Rani Durgawati University, Jabalpur 482001, India \\ MS received 7 October 1983
}

\begin{abstract}
A bstract. The temperature dependence of microhardness of mixed $\mathrm{KCl}-\mathrm{KBr}$ crystals has been studied using the Kataoka and Yamada theory which considers plastic deformation and internal stress field due to elastic interactions in mixed crystals. The microhardness showed systematic variation with temperature in both the components and the mixed crystals and the probable reasons for this variation are indicated.
\end{abstract}

Keywords. Mixed crystals; microhardness; temperature dependence; Kataoka-Yamada theory.

\section{Introduction}

In recent years, considerable attention has been paid to the study of mixed crystal properties as they are useful in many technological applications (e.g. mixed crystals of alkali halides are used for laser windows). One well-known property is microhardness, which for mixed crystals always exceeds its value for the component crystals (Armington et al 1973; Hari Babu et al 1975). A number of theories (Gilman 1973; Shukla and Bansigir 1976; Boser 1972; Ridhagani and Asimow 1968) have been proposed to explain this extra hardness of mixed crystals. Earlier theories of Gilman (1973) and Shukla and Bansigir (1976) could not explain the microhardness of mixed crystals as indicated by Bhimshankaran (1974), and Srivastava (1980). Kataoka and Yamada (1977) have given a theory according to which the random distribution of doped ions can produce an internal stress field interaction that increases the microhardness of the mixed crystals. This theory has been applied to mixed alkali halides (Srivastava 1980) and mixed silver halides (Sanyal and Singh 1982).

Motivated by the success of the theory of Kataoka and Yamada theory, we have applied it to study the temperature dependence of microhardness of $\mathrm{KCl}_{x} \mathrm{Br}_{1-x}$ system from 300-1000 K. It is known (Subba Rao and Hari Babu 1978) that the excess of microhardness in mixed crystals results from the increased value of dislocation density. However, this dislocation density in mixed crystals decreases with increase in temperature. Thus, it seems worthwhile to investigate the exact nature of change of microhardness with temperature in mixed crystals. Srivastava (1980) used the KataokaYamada theory to explain the microhardness of $\mathrm{KCl}_{x} \mathrm{Br}_{1-x}$, measured by Subba Rao and Hari Babu (1978) at $300 \mathrm{~K}$ only. In doing so, he used the measured microhardness values of $\mathrm{KCl}, \mathrm{KBr}$ and $\mathrm{KCl}_{0.48} \mathrm{Br}_{0.52}$ as the input data. Thus, the predictions made by Srivastava are more or less borne out. In the present analysis, however, the results of microhardness of $\mathrm{KCl}_{0.48} \mathrm{Br}_{0.52}$ have only been used at $300 \mathrm{~K}$ to determine a parameter. The values of microhardness of component crystals $(\mathrm{KCl}$ and $\mathrm{KBr})$ have been obtained in terms of Debye temperatures (Bollmann 1980). 


\section{Theory}

The microhardness $\left(H_{v}\right)$ of binary ionic solids is related to the Schotky defect formation energy $\left(w_{s}\right)$ as (Shukla and Bansigir 1976)

$$
H_{v}=205.8 W_{s} / r^{3},
$$

where $r$ is the interionic separation. According to Sastry and Mulimani (1969), $W_{s}$ is also related to the Debye temperature $\left(\Theta_{D}\right)$, such that

$$
W_{s}=\left(\Theta_{D} / 32.37\right)^{2} M V^{2 / 3} \text {. }
$$

Here, $M$ and $V$ are the molar mass and volume. Now, $H_{u}$ can be written in terms of the Debye temperature as:

$$
H_{v}=6.833\left(M V^{2 / 3} / r^{3}\right) \Theta_{D}^{2} \times 10^{-5}\left(\mathrm{~kg} / \mathrm{mm}^{2}\right),
$$

from (1) and (2). This equation is, however, valid only for the component crystals and not for mixed crystals, as it fails to account for the extra hardness in them. We have therefore considered the extra hardness using the Kataoka-Yamada theory in which the doped ions are assumed to behave as a source of constriction and expansion in the lattice in order to maintain the crystal symmetry. The random distribution of these ions produces a fluctuating stress in the mixed crystals and is responsible for the increase in their hardness. The mean expectation value of the internal stress, $\tau_{0}$, arising from the random distribution of anions is given by (Kataoka and Yamada 1977)

$$
\tau_{0}=\frac{4 \sqrt{2}}{\pi} \alpha\left(\frac{\alpha}{\alpha^{\prime}}\right)^{1 / 2} \frac{\sigma^{2} r^{2}}{\lambda}\left(\frac{\Delta V}{r^{3}}\right) \beta_{1} \beta_{2},
$$

where $\alpha$ and $\alpha^{\prime}$ are the lattice sums. $\Delta V$ is the difference in anion volume of the two components and $\beta_{1}$ and $\beta_{2}$ are fractional molar concentrations of the two components in the mixed crystals. The symbols $\sigma$ and $\lambda$ are related to the second order elastic constants by

and

$$
\sigma=\frac{1}{2}\left(C_{11}-C_{12}\right)
$$

$$
\lambda=\frac{1}{2}\left(C_{11}+C_{12}\right)\left[\frac{C_{44}\left(C_{11}-C_{12}\right)}{C_{11}\left(C_{11}+C_{12}+C_{44}\right)}\right]^{1 / 2} r^{2} .
$$

In terms of $\tau_{0}$ the hardness due to internal stress field can be expressed as

$$
H_{\text {isf }}=F \tau_{0}
$$

with $F$ as a constant. Thus, the microhardness of mixed crystals is ultimately given by

$$
H_{m}=\beta_{1} H_{1}+\beta_{2} H_{2}+H_{\text {isf }},
$$

where $H_{1}$ and $H_{2}$ are the hardness of the component crystals.

\section{Results and discussion}

The microhardness $\left(H_{v}\right)$ values of the component crystals, $\mathrm{KCl}$ and $\mathrm{KBr}$ at different temperatures (300-1000 K) were calculated from (3) using the values of Debye temperature $\left(\Theta_{D}\right)$ and interionic separation $\left(r_{0}\right)$ reported by Tolpadi (1977) and 
Subramaniam (1979). Their values for $\mathrm{KCl}$ and $\mathrm{KBr}$ at different temperatures are listed in table 1 and are compared with their measured data at $300 \mathrm{~K}$ (Bollman 1980; Subba Rao and Hari Babu 1978). The microhardness $\left(H_{m}\right)$ values for the mixed crystals at different temperatures have been calculated from (8) using the required values of elastic constants reported by Subramaniam (1978). The variations of microhardness with temperature for the component crystals and mixed $\mathrm{KCl}-\mathrm{KBr}$ are presented in figure 1 and those with mole percentage of $\mathrm{KBr}$ are presented in figure 2 .

Table 1. Microhardness $\left(H_{\iota}\right)$ of $\mathrm{KCl}$ and $\mathrm{KBr}$ at different temperatures.

\begin{tabular}{ccl}
\hline \multirow{2}{*}{$\begin{array}{c}\text { Temper- } \\
\text { ature } \\
(\mathrm{K})\end{array}$} & \multicolumn{2}{c}{$H_{v}\left(\mathrm{~kg} / \mathrm{mm}^{2}\right)$} \\
\cline { 2 - 3 } & $\mathrm{KCl}$ & $\mathrm{KBr}$ \\
\hline 300 & 10.306 & 8.468 \\
& $9.9^{a}$ & $7.9^{b}$ \\
400 & 9.464 & 8.231 \\
500 & 8.906 & 7.785 \\
600 & 8.317 & 7.329 \\
700 & 7.706 & 6.847 \\
800 & 7.020 & 6.331 \\
900 & 6.236 & 5.784 \\
1000 & 5.293 & 5.133 \\
\hline
\end{tabular}

a Bolmann (1980); ${ }^{b}$ Subba Rao and Hari Babu (1978).

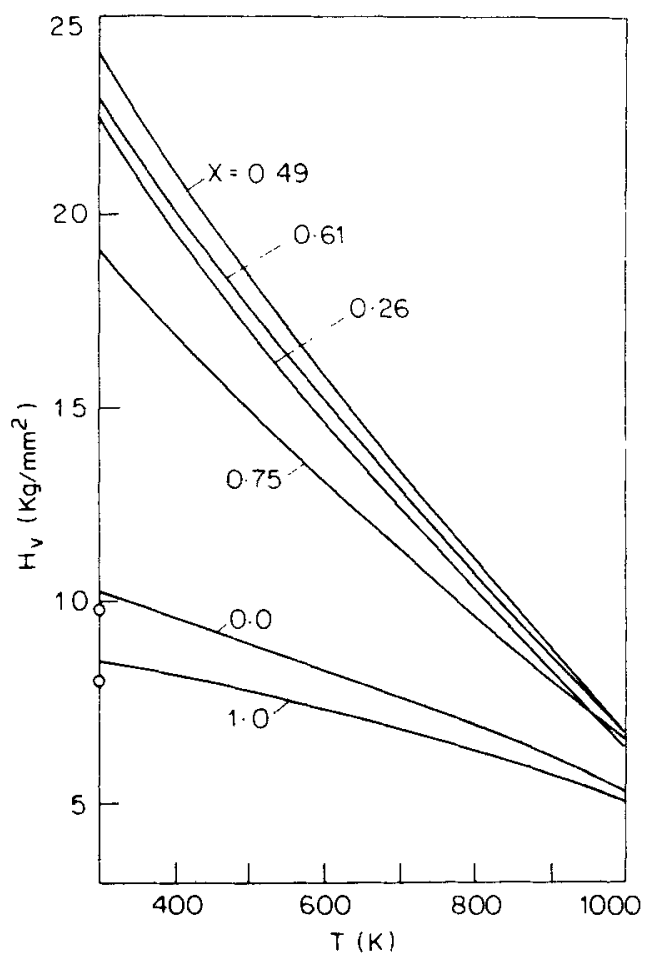

Figure 1. Variation of microhardness of $\mathrm{KCl}_{x} \mathrm{Br}_{1-x}$ system with temperature. Experimental points (o) at $300 \mathrm{~K}$ have been taken from Subba Rao and Hari Babu (1978). 


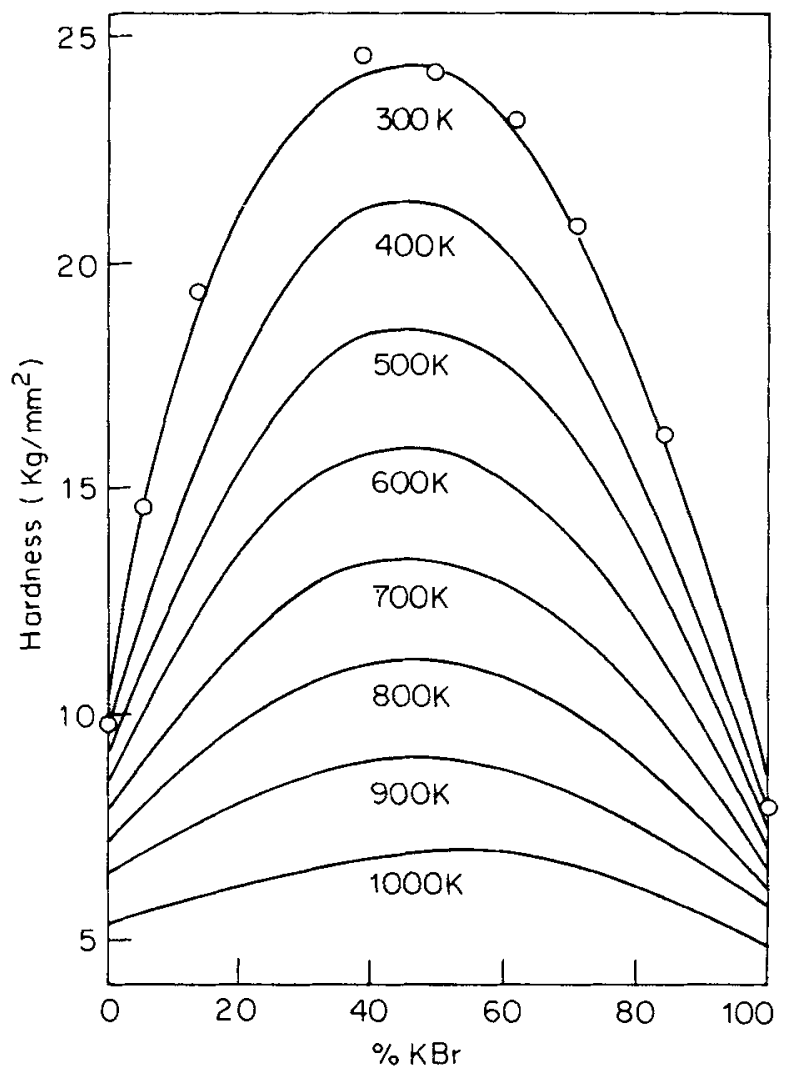

Figure 2. Variation of microhardness of $\mathrm{KCl}_{x} \mathrm{Br}_{1-x}$ system with $\%$ of $\mathrm{KBr}$ in $\mathrm{KCl}$ at different temperatures. Experimental points are taken from Subba Rao and Hari Babu (1978).

Table 1 shows that the microhardness of the component crystals can be satisfactorily predicted by using (3). These values decrease almost linearly with temperature as shown in figure 1. This might be so because the microhardness is a measure of the resistance offered by dislocation motion which becomes easier when the temperature is raised. The variation of $H_{v}$ with temperature in mixed crystals is, however, not linear, perhaps due to the elastic effects arising from the size misfit of cations.

Figure 2 shows that the extra hardness in mixed crystals (Hari Babu and Subba Rao 1978 ) at $300 \mathrm{~K}$ has been adequately explained even without using the $H_{v}$ values of the component crystals. This prediction is better than that achieved by Subba Rao and Hari Babu (1978) where they neglected the effects due to elastic interactions (Kataoka and Yamada 1977). Our results on $H_{v}$ at higher temperatures could not be compared due to lack of measured data. Their variation with temperature is, however, systematic and consistent with the measured results in other solids (Bhatt and Desai 1982).

\section{References}

Armington A F, Posen H and Lipson H 1973 J. Electron. Mater. 2127

Bhatt V P and Desai C F 1982 Bull. Mater. Sci. 423 
Bhimasankaran T 1974 Ph.D. Thesis, Osmania University, AP

Bollman W 1980 Phys. Status Solidi A6 395

Boser O 1972 Metall. Trans. 3843

Gilman J J 1973 J. Appl. Phys. 44983

Hari Babu V, Subba Rao U V and Venkata Ramaiah K 1975 Phys. Status Solidi A28 269

Kataoka T and Yamada T 1977 Jpn J. Appl. Phys. 161119

Riddhagni B R and Asimow R M 1968 J. Appl. Phys. 394164

Sanyal S P and Singh R K 1982 J. Phys. D15 1083

Sastry P V and Mulimani P Ǵ 1969 Philos. Mag. 20859

Shukla M and Bansigir K G 1976 J. Phys. D9 L49

Srivastava U C 1980 J. Appl. Phys. 511510

Subba Rao U V and Hari Babu V 1978 Pramana 11149

Subramaniam B 1979 Indian J. Phys. A54 109

Tolpadi S 1977 Indian J. Phys. A51 181 